\title{
Sudden infant death syndrome in Hong Kong: confirmation of low incidence
}

Department of Paediatrics, Prince of Wales Hospital, Chinese University of Hong Kong, Shatin, Hong Kong Natalie N Y Lee, MRCP, lecturer

D P Davies, FRCP, professor

Clinical Pathology Unit, Princess Margaret Hospital, Kowloon

Y F Chan, MRCPATH, consultant pathologist

Department of Community Medicine, Chinese

University of Hong Kong,

Hong Kong

E Lau, MB, lecturer

Forensic Pathology

Service, Medical and

Health Department, Hong

Kong

David C P Yip, MB,

consultant forensic pathologist

Correspondence to: Dr Lee.

BrMed f 1989;298:721

\section{Natalie N Y Lee, Y F Chan, D P Davies, E Lau, David C P Yip}

We carried out a prospective study to investigate an earlier retrospective finding of a low incidence of the sudden infant death syndrome in Hong Kong. ${ }^{1}$

\section{Patients, methods, and results}

Hong Kong has a population of five and a half million, $98 \%$ being Chinese. It is mandatory for a necropsy to be performed on any person found dead outside hospital. Such necropsies are performed only in two government public mortuaries.

We examined infants aged 1 to 12 months found 30 November 1987 in whom there was no immediately obvious cause. of death-for example, congenital abnormalities and trauma. Necropsies were performed by YFC and a pathologist from the Hong Kong government forensic pathology service. If the sudden infant death syndrome was diagnosed two doctors (NNYL and YFC) arranged a visit to the parents' home to gather information about the death and details of the family, pregnancy and neonatal events, later morbidity, and methods of child care. To ascertain unexpectedly dead at home from 1 December 1986 to

Social, pregnancy, neonatal, and later morbidity details and methods of child care among 16 cases of the sudden infant death syndrome and 32 matched controls. Figures are numbers of subjects unless otherwise stated

\begin{tabular}{|c|c|c|c|}
\hline & \multirow[b]{2}{*}{ Cases $(n=16)$} & \multicolumn{2}{|c|}{ Controls } \\
\hline & & Hospital $(n=16)$ & Community $(n=16)$ \\
\hline \multicolumn{4}{|l|}{ Mother: } \\
\hline Mean $(\mathrm{SD})$ age (years) & $28(5)$ & $29(3)$ & \\
\hline Age $<21$ years & 1 & 0 & 0 \\
\hline Smoker & 0 & 0 & 0 \\
\hline Married & 16 & 16 & \\
\hline \multicolumn{4}{|l|}{ Father: } \\
\hline Mean $(\mathrm{SD})$ age $($ years $)$ & $33(5)$ & $33(4)$ & \\
\hline Employed & 16 & 15 & 16 \\
\hline Smoker & 8 & 3 & 4 \\
\hline \multicolumn{4}{|l|}{ Accommodation: } \\
\hline Privately owned or rented house or flat & 8 & 4 & 7 \\
\hline Low cost, government or public subsidised & 6 & 9 & 5 \\
\hline Other (squat, stone or wood hut, boat or junk) & 2 & 3 & 4 \\
\hline \multicolumn{4}{|l|}{ Neonatal details: } \\
\hline \multicolumn{4}{|l|}{ Birth weight: } \\
\hline $\operatorname{Mean}(\mathrm{SD})(\mathrm{g})$ & $3080(710)$ & $3080(620)$ & $3020(70)$ \\
\hline$<2500 \mathrm{~g}$ & 4 & 1 & 0 \\
\hline \multicolumn{4}{|l|}{ Gestation: } \\
\hline Mean (SD) (weeks) & $39(2)$ & $39(3)$ & $39(1)$ \\
\hline$<37$ Weeks & $1^{\star}$ & 1 & 1 \\
\hline Congenital abnormalities & $2 \dagger$ & 0 & 0 \\
\hline Other problems & 0 & $1 \neq$ & 0 \\
\hline Breast fed & 0 & 1 & 1 \\
\hline \multicolumn{4}{|l|}{ Parity: } \\
\hline 1st Born & 4 & 4 & 7 \\
\hline 2nd And subsequent & 12 & 12 & 9 \\
\hline \multicolumn{4}{|l|}{ Later morbidity: } \\
\hline Previous admission to hospital & $4 !$ & 4 & 15 \\
\hline \multicolumn{4}{|l|}{ Usual place of sleeping: } \\
\hline Parents' sleeping area & 12 & 14 & 13 \\
\hline Same bed as parents & 2 & 4 & 5 \\
\hline \multicolumn{4}{|l|}{ Other room or partitioned area } \\
\hline with someone else & 4 & 2 & 2 \\
\hline Alone in separate room & 0 & 0 & 1 \\
\hline \multicolumn{4}{|l|}{ Usual sleeping posture: } \\
\hline Supine & 9 & 16 & 14 \\
\hline Prone & 79 & 0 & 2 \\
\hline \multicolumn{4}{|l|}{ Posture at time of death: } \\
\hline Supine & 6 & & \\
\hline Prone & 10 & & \\
\hline
\end{tabular}

$\star 31$ Weeks.

tCleft palate (1), emphalocele (1).

fIdiopathic respiratory distress syndrome.

Respiratory infection.

Respiratory infection (2), gastroenteritis (1), poor feeding (1)

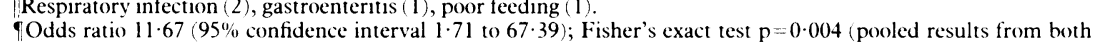
Odds ration
controls). possible local risk factors we selected two control babies, one in hospital and one from the community, for each index baby, who were matched for sex and had been born within one week of the dead infant. The odds ratios were calculated from unmatched analysis and pooling both controls. The $\chi^{2}$ test or Fisher's exact test was applied when appropriate.

Fifty one dead infants were transferred for necropsy. The sudden infant death syndrome was diagnosed in nine boys and 12 girls, all ethnic Chinese. Thirteen died under the age of 3 months, five from 3 to under 6 months, and three from 6 to 9 months. The deaths were fairly evenly distributed throughout the year except in December, when seven babies died; this was more than double the usual monthly incidence. With 70519 births during the study the incidence of the sudden infant death syndrome was $0 \cdot 3 / 1000$ live births.

Parents of 16 infants were interviewed; the remaining five could not be contacted or declined the visit. The table gives details of data collected for cases and controls. The only significant difference between cases and controls concerned the usual sleeping posture. Two $(7 \%)$ of the 32 control babies were reported to have slept usually in a prone position, compared with seven $(44 \%)$ of the 16 babies who died $(p=0.004)$.

\section{Comment}

Because necropsies after unexpected deaths are done in only two places in Hong Kong we are confident that all cases of the sudden infant death syndrome during the study were included. The incidence we found $(0 \cdot 3 / 1000)$ was higher than the $0 \cdot 04 / 1000$ reported previously.' This was probably because of differences in diagnostic criteria at necropsy.' The sudden infant death syndrome clearly occurs much less often in Hong Kong than in many Western countries (approximate incidence $\left.2-4 / 1000^{3}\right)$. The demographic pattern also differs, with a slight preponderance among girls, a peak incidence below 2 months, absence of young parents, no obvious high prevalence of low birth weight and prematurity, and no excess previous morbidity. The syndrome did not seem so influenced by social deprivation as in many Western countries.

We speculate that greater environmental stimulation arising from crowded living conditions and a tradition of using a supine sleeping posture to avoid suffocation might, at a time when the mechanism of control of breathing is changing, ${ }^{+}$influence respiratory patterns; this might reduce vulnerability to sudden death from apnoea, as recently alluded to by McKenna. ' Methods of child care might play a more important part than has been previously thought in the aetiology of the sudden infant death syndrome and deserve further attention.

We thank Drs K S Khin, R Khoo, B Shum, H W Yu, K L $\mathrm{Hau}$, and $\mathrm{H} \mathrm{K}$ Mong, pathologists of the Victoria and Kowloon public mortuaries, for their help and collaboration; Professor J Emery (Sheffield) and Dr A Gibson (Glasgow) for their expert help in examining some of the histological sections from necropsy; Mrs Connie Cheng for typing the manuscript.

I Davies DP. Cot death in Hong Kong: a rare problem? Luncet 1985:ii: 13+6-8. 2 Yip DCP, Khin Khin Sein, Hau KL. A retrospective studs of interstitial pneumonitis ciral pneumonia as a cause of sudden and unexpected natural death. Med Sil Law 1987:27:79-84

3 Kelly DH, Shannon DC. Sudden infant death syndrome and near sudden infant death syndrome: a review of the literature $196+$ to 1982. Pediatr Clin North Am 1982:29:12+1-61.

+ Lipsitt JP. The importance of collaboration and developmental follow-up in the study of perinatal risk. In: Smeriglio VL, ed. Newborns and puremts: parent study of perinatal risk. In: Smeriglio VL, ed. Newhorns and parents: parent
infant contact and neteborm sensorn stimulation. Hillsdale: Lawrence Erlhaum infant comtact and nerchom

5 McKenna JJ. An anthropological perspective on the sudden infant death syndrome (SIDS : the role of parental breathing cues and speech breathing adaptation. Med Anthropol 1986;10:9-53.

(Accepted 20 fanuur. 1989 